\title{
A NOVEL ANGIOGENESIS INHIBITOR BEVACIZUMAB INDUCES APOPTOSIS IN THE RAT ENDOMETRIOSIS MODEL
}

\author{
Soysal D 1,*, Kızıldağ S2,*, Saatlı B ${ }^{1}$, Posacı C ${ }^{1}$, Soysal S ${ }^{3}$, Koyuncuoğlu $\mathrm{M}^{4}$, Doğan ÖE
}

*Corresponding Author: Sefa Kızıldağ, Ph.D., Dokuz Eylül University, Faculty of Medicine, 35340 İnciralti, İzmir, Turkey. Tel.: +90-2324124613. Fax:+90-2322590541. E-mail:sefa.kizildag@deu.edu.tr

\begin{abstract}
Our aim was to investigate the effects of antivascular endothelial growth factor (anti-VEGF) antibody Bevacizumab on endometrial explants and on apoptotic gene expression levels in the rat endometriosis model. Endometriotic implants were surgically formed, and rats treated with (i) $1 \mathrm{mg} / \mathrm{kg}$ single subcutaneous injection of depot leuprolide acetate; (ii) $2.5 \mathrm{mg} / \mathrm{kg}$ of single intaperitoneal injection of bevacizumab; (iii) intraperitoneal injection of saline. Histopathologic scores and adhesion scores of endometriotic foci and levels of Bcl-2-associated X protein (Bax), Cytochrome c (Cyt-c), B-cell lymphoma/leukemia 2 (Bcl-2) and B-cell lymphoma-extra large ( $B c l-x l)$ mRNA gene expressions of endometriotic foci. Bevacizumab treatment decreased the endometriotic explant size compared with control. Bevacizumab-treated rats had lower total adhesion scores when compared with the control group. Semiquantitative evaluation of the persistence of endometrial epithelial cells in the explants showed a lower score in gonadotropin-releasing hormone $(\mathrm{GnRH})$ agonist-treated rats compared with control rats. In
\end{abstract}

\footnotetext{
${ }^{1}$ Dokuz Eylül University, Obstetrics and Gynecology, 35340, İzmir, Turkey

${ }^{2}$ Dokuz Eylül University, Medical Biology and Genetics, 35340, İzmir, Turkey

${ }^{3}$ Menemen State Hospital, Obstetrics and Gynecology, 35660, İzmir, Turkey

${ }^{4}$ Dokuz Eylül University, Pathology, 35340, İzmir, Turkey
}

Bevacizumab increased expression of Bax 3.1-fold, $\mathrm{Cyt}-\mathrm{c}$ 1.3-fold and decreased expression of $\mathrm{Bcl}-2$ 0.4-fold, $B c l$ - $x l$ 0.8-fold compared with the control group. The GnRH agonist increased expression of Bax 3.0 fold, $C y t-c 1.3$ fold and decreased expression of $B c l-2$ 0.4-fold, $B c l-x l 0.8$-fold, compared with the control group. This study suggests that a novel angiogenesis inhibitor, anti-VEGF antibody bevacizumab is as effective as GnRH agonist in the regression of the endometriotic lesions in rat endometriosis model. One possible mechanism of this effect is the induction of apoptosis.

Keywords: Endometriosis; Apoptosis; Bevacizumab; Angiogenesis.

\section{INTRODUCTION}

Endometriosis is defined as the presence of a functional endometrial layer with endometrial glands and stroma outside the uterine cavity. Dismenorhea, disparonea, pelvic pain and infertility are common symptoms. The incidence of the disease is $15.0-25.0 \%$ in reproductive age and it increases up to $20.0-40.0 \%$ in infertile women $[1,2]$.

The morphologic appearance of endometriosis is marked by proliferation, infiltration and severe adhesions around the surrounding tissues. Research into its pathogenesis has focused on anatomic, hormonal, immunologic and genetic factors [3], although the etiopathology has not yet been clearly explained. However, endometriosis should be accepted as an estrogen-dependent condition because it is seen during 
the reproductive years and generally disappears after menopause. Conventional treatment modalities are based on deprivation of estrogen locally and systematically. Unfortunately, this treatment can have serious implications for fertility, and long-term treatment strategies cannot be applied because of side effects.

Neovascularization is essential for survival and growth of exfoliated endometrium. Vascular endothelial growth factor (VEGF) is a heparin-binding angiogenic growth factor of 30 to $40 \mathrm{kd}$, a mediator of neovascularization. It increases vascular permeability and is needed for survival of newly formed blood vessels. Vascular endothelial growth factor is involved in both the cause and maintenance of peritoneal endometriosis [4].

The effect of the VEGF can be inhibited by receptor inhibition, VEGF receptor tyrosine kinase inhibition and monoclonal antibodies against VEGF. Bevacizumab is a recombinant humanized IgG1 antibody that binds to VEGF and terminates its biologic activity. It shows its activity in the tissue by inhibiting angiogenesis. The anti-VEGF effect of bevacizumab has been shown in many human cancers (5). Animal studies reveal that the decrease in tumor size is due to apoptosis which is caused by inhibition of angiogenesis [6-8]. This suggests that there is a close relationship between angiogenesis and apoptosis.

Apoptosis is an important factor in etiopathogenesis of the endometriosis. There is a marked decrease in apoptosis levels in endometriotic women's endometrial tissue compared with normal women. This difference is even shown in exfoliated endometrial tissue of endometriosis patients [9]. Apoptosis is regulated by pro-apoptotic and anti-apoptotic genes. The $B$ cell lymphoma/leukemia $2(B c l-2)$ gene was first identified in follicular B cell lymphoma; up to now more than $20 \mathrm{Bcl}-2$ family member genes have been defined. These genes show their effects by inducing or inhibiting apoptosis. Bcl-2, B-cell lymphoma-extra large $(B c l-x l)$ are anti-apoptotic members and the Bcl-2-associated X protein (Bax) gene is a pro-apoptotic member [10]. Cytochrome$\mathrm{c}$ is a mitochondrial protein that is released in case of mitochondrial damage and plays role in intrinsic pathway of apoptosis [11]. The aim of this study was to investigate the effects of anti-VEGF antibody Bevacizumab on endometrial explants, on adhesion formation and on apoptotic gene expression levels in the rat endometriosis model.

\section{MATERIALS AND METHODS}

Thirty-five female Wistar albino mature rats at 8 weeks, weighing 200-250 g, were used for the study. Animals were housed in steel cages with free access to food and water. The temperature of the environment was controlled within $24{ }^{\circ} \mathrm{C}$ and 12-hour light/dark cycles were maintained. The experimental procedures were approved by the institutional review board of Dokuz Eylül University, İzmir, Turkey. The induction of endometriosis was conducted by the method described by Vernon and Wilson [12]. All rats were anesthetized, using ketamine hydrochloride at a dose of $40-80 \mathrm{mg} / \mathrm{kg}$, and $5-10 \mathrm{mg} / \mathrm{kg}$ of xylazine hydrochloric was administered intraperitoneally. The abdomen was opened through a $5 \mathrm{~cm}$ midline incision. The left uterine horn was ligated at both the uterotubal junction and the cervical end, and removed. The excised horn was immersed in sterile saline solution, the endometrium was exposed by bisecting along its antimesenteric axis and $5 \times 5 \mathrm{~mm}$ sections were cut. These explants were then anchored onto the peritoneum on the left side of the ventral abdominal wall close to an artery by 5-0 polypropylene sutures. Abdominal layers were closed anatomically, using 3-0 polyglactin 910 sutures and the animals were allowed to recover from anesthesia. Three rats died in the first week of the initial surgery. Three weeks after the initial surgery, each rat was anesthetized and a midventral laparotomy was performed to determine the attachment and viability of endometrial explants. The surface areas of the explants were measured (length $\times$ width). Twenty-nine of the 32 rats $(90.6 \%)$ had viable and well vascularized endometrial explants in the second laparotomy. Twenty-nine rats were randomly divided into three groups. The GnRH agonist group was treated with a single subcutaneous injection of GnRH analog, leuprolide acetate depot formulation (1 mg/kg body weight) (Lucrin Depot; Abbott Laboratories, Abbott Park, IL, USA). The Bevacizumab group was given a single intraperitoneal injection of bevacizumab (2.5 mg/kg body weight) (Avastin; Genentech/Roche, San Francisco, CA, USA). The Control group received saline solution as placebo by gastric lavage. Three weeks after treatment, a third laparotomy was performed. After a midline incision, the endometrial explants were measured and the level of the adhesions were scored macroscopically by the method defined by Linsky et al. in 1987 [13]. The 
severity of the adhesions was scored as follows: 0 point no resistance to separation, 0.5 point partial resistance to separation, 1 point sharp dissection was needed. The extension of the adhesions was scored as: 0 point no adhesions; 1 point $25.0 \%$ of traumatized area; 2 points $50.0 \%$ of traumatized area; 3 points total involvement. The total grade was additive, giving a range of adhesion scores from 0 to 4 , which represented both extent and severity of adhesions. These measurements and evaluations were made by one operator blinded to the study. For histologic examination and apoptosis assays, endometriotic explants were excised. A small part of endometrial explant was kept for polymerase chain reaction (PCR) study and the remainder was fixed in $10.0 \%$ formalin. The formalin-fixed endometriotic foci were embedded in paraffin blocks, sectioned at $\sim 5 \mathrm{~mm}$ thickness (four sections per sample), stained with hema-toxylin-eosin and CD10 (a $94 \mathrm{kDa}$ zinc-dependent cell membrane metalloprotein that participates in the postsecretory processing of neuropeptides) immunohistochemistry and examined under a light microscope (Figure 1). The pathologist assessing the samples was blinded to the treatment groups. The persistence of epithelial cells in endometrial explants was semiquantitatively evaluated as follows: 3 , well-preserved epithelial layer; 2 , moderately preserved epithelium with leukocyte infiltrate; 1 , poorly preserved epithelium (occasional epithelial cells only) and 0 , no epithelium. This evaluation was based on a previous rat endometriosis study [14]. All rats were sacrificed at the end of study.

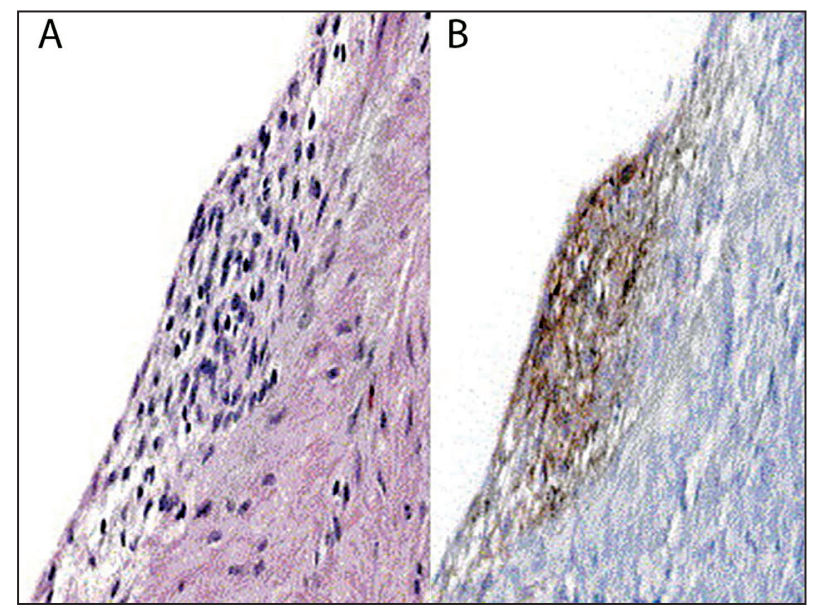

Figure 1. Light microscopy (magnification '20) of a surgically identified endometriosis lesion.

A) Stained with hematoxylin-eosin;

B) CD10 immunohistochemistry.
Total RNA Extraction and cDNA Synthesis. Total RNA was extracted from cells using High Pure RNA isolation Kit according to the protocol provided by Roche Diagnostics (Basel, Switzerland). Complementary DNAs (cDNAs) were synthesized from $2 \mathrm{mg}$ of the total RNA with SuperScript FirstStrand Synthesis System for reverse transcriptionPCR (RT-PCR) according to the protocol provided by Invitrogen (Carlsbad, CA, USA). The mixture was incubated at $42^{\circ} \mathrm{C}$ for $50 \mathrm{~min} ., 72^{\circ} \mathrm{C}$ for $15 \mathrm{~min}$. After the addition of $2 \mathrm{U}$ RNase $\mathrm{H}$, the PCR was per-formed in a volume of $20 \mu \mathrm{L}$ containing $2 \mu \mathrm{L}$ cDNA.

Real-Time Reverse Transcription-Polymerase Chain Reaction. Real-time PCR was carried out using a Light Cycler ${ }^{\circledR} 2.0$ instrument and FastStart TaqMan Probe Master kit (both from Roche Diagnostics). Reactions were performed in a $20 \mu \mathrm{L}$ volume with 5 pmol of each primer and $2 \mu \mathrm{L}$ of cDNA template derived from reverse-transcribed RNA of the GnRH agonist group, Bevacizumab group and Control group tissue cells. A hypoxanthine phosphoribosyl-transferase (HPRT) housekeeping gene was used as endogenous control and reference gene for relative quantifications. Sequences of oligonucleotide pri-mers were as follows: HPRT (F) 5'-GTG GAG ATG ATC TCT CAA CT-3', HPRT (R) 5'-ACA TGA TTC AAA TCC CTG AAG-3', BAX (F) 5'-AAG AAG CTG AGC GAG T-3', BAX (R) 5'-GCC CAT GAT GGT TCT G-3', CYC (F) 5'-TGG GTG ATG TTG AGA AAG G-3', CYC (R) 5'-TTT GTT CCA GGG ATG TAC T-3', BCL XL (F) 5'-GCT GGT GGT TGA CTT TC-3', BCL XL (R) 5'-GGA TGG GTT GCC ATT GA-3', BCL-2 (F) 5'-ACC TGA CGC CCT TCA C-3', BCL-2 (R) 5'-AGG TAC TCA GTC ATC CAC-3'. The same thermal profile was optimized for all primers: a pre incubation for 10 min. at $95^{\circ} \mathrm{C}$, followed by 40 amplification cycles of denaturation at $95^{\circ} \mathrm{C}$ for 10 seconds, primer annealing at $59^{\circ} \mathrm{C}$ for 5 seconds, and pri-mer extension at $72{ }^{\circ} \mathrm{C}$ for 10 seconds. Distilled water was included as a no template control. Melting curves were derived after 40 cycles by a denaturation step at $95^{\circ} \mathrm{C}$ for 10 seconds, followed by annealing at $65^{\circ} \mathrm{C}$ for 15 seconds, and a temperature rise to $95^{\circ} \mathrm{C}$ with a heating rate of $0.1{ }^{\circ} \mathrm{C} /$ second and continuous fluorescence measurement. Final cooling was performed at $40{ }^{\circ} \mathrm{C}$ for 30 seconds. Melting curve analyses of each sample were done using LightCycler Software version 4.0.0.23 (Roche Diagnostics). The analysis 


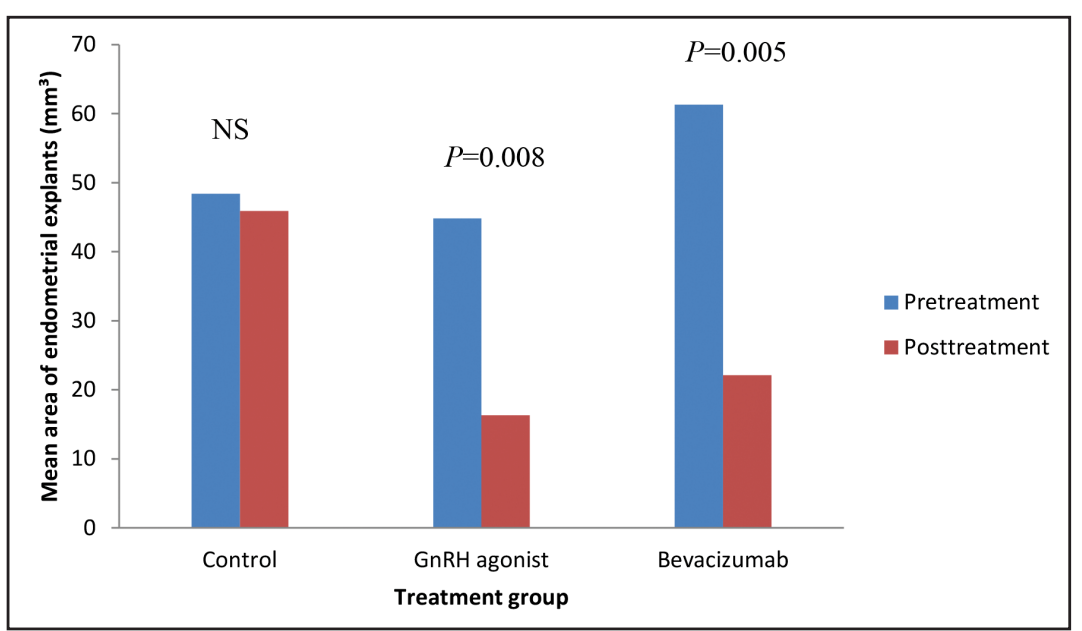

Figure 2. Change in the mean area of endometriotic explants in treatment groups. NS: not statistically significant.

step of relative quantification was a fully automated process done by the software, with the efficiency set at 2 and the cDNA of untreated cells defined as the calibrator. All experiments were done in triplicate.

Statistical Analyses. The statistical analyses were performed using the Statistical Package for the Social Sciences version 16.0 (SPSS Inc., Chicago, IL, USA). Non normally distributed metric variables, adhesion scores, histopathologic scores and gene expression levels were analyzed by the Kruskal-Wallis test and Mann-Whitney U-test. The mean surface areas of the endometriotic explants between the same group (before and after medical treatment) were analyzed by Wilcoxon's signed-rank test. $p$ Values of $<0.05$ were considered statistically significant. Values were expressed as mean \pm standard deviation (SD), unless stated otherwise.

\section{RESULTS}

At the beginning of the medical treatment, the mean surface areas of the endometriotic explants were comparable in all three groups $(\mathrm{GnRH}$ agonist group; $44.8 \pm 39.2$, bevacizumab group $2 ; 61.3 \pm$ 41.1, control group; $48.4 \pm 32.8, p=0.412$ ). After treatment with saline solution there was no statically significant change in mean explant size in the control group $(48.4 \pm 32.8 \mathrm{~mm} 2$ vs. $45.9 \pm 33.7 \mathrm{~mm} 2 ; p=$ $0.483)$. However, there was a statistically significant decrease in the mean explant sizes 3 weeks after treatment in both the GnRH agonist group (44.8 \pm $39.2 \mathrm{~mm} 2$ vs. $16.3 \pm 15.1 \mathrm{~mm} 2 ; p=0.008)$ and the bevacizumab group $(61.3 \pm 41.1 \mathrm{~mm} 2 v s .22 .1 \pm 16.1$ $\mathrm{mm} 2 ; p=0.005)$ (Figure 2). The decreases in the explant sizes were $6.2,61.9$ and $58.8 \%$ for the control, GnRH agonist and bevacizumab groups, respectively. Bevacizumab treatment statistically significantly decreased the endometriotic explant size $(58.8 \%)$ compared to the control group $(6.2 \%)(p<0.001)$, and this effect was comparable with the decrease in GnRH agonist (61.9\%) $(p=0.62)$.

Semiquantitative evaluation of the persistence of endometrial epithelial cells in the explants showed a significantly lower score in the GnRH agonist group $(0.56 \pm 1.0)$ compared with the control group (1.78 $\pm 1.0)(p=0.009)$, but the bevacizumab-treated rats $(1.4 \pm 1.4)$ had similar scores as the control group $(p=0.445)$. There was no statistically significant difference in semiquantitative evaluation between the bevacizumab and GnRH agonist groups $(p=0.168)$.

The extent, severity and the total scores of the adhesions were measured after the third laparotomy. The severity, extent and total adhesion scores were significantly reduced in the bevacizumab treated group compared to the control group $(p<0.05)$. There were no statically significant difference between $\mathrm{GnRH}$ agonist treated rats compared with the control group and bevacizumab group $(p>0.05)$ as shown in Table 1.

In the PCR study of endometrial explants apoptotic genes (Bax, Cyt-c) and anti-apoptotic genes $(B c l-2, B c l-x l)$ levels were evaluated (Table 2). In endometrial explants bevacizumab statistically significantly increased expression of the Bax gene 3.1-fold, $C y t-c$ gene 1.3-fold and decreased expression of the $B c l$-2 gene 0.4-fold, $B c l-x l$ gene 0.8-fold compared 
Table 1. The extent, severity and total scores of treatment groups.

\begin{tabular}{|l|c|c|c|c|}
\hline Variable & Control $(\boldsymbol{n}=\mathbf{1 0})$ & GnRH Agonist $(\boldsymbol{n}=\mathbf{9})$ & Bevacizumab $(\boldsymbol{n}=\mathbf{1 0})$ & $\boldsymbol{p}$ Value \\
\hline Extent of adhesion & $2.1 \pm 0.7$ & $1.6 \pm 0.9$ & $1.0 \pm 0.7$ & 0.017 \\
\hline Severity of adhesion & $0.8 \pm 0.3$ & $0.6 \pm 0.4$ & $0.4 \pm 0.3$ & 0.30 \\
\hline Total score of adhesion & $2.9 \pm 0.9$ & $2.2 \pm 1.3$ & $1.4 \pm 0.9$ & 0.011 \\
\hline
\end{tabular}

Values are mean \pm standard error of mean (SEM).

Table 2. Pro-apoptotic and anti-apoptotic gene expressions in treatment groups.

\begin{tabular}{|l|c|c|c|c|}
\hline Endometrial Explant & Control $(\boldsymbol{n}=\mathbf{1 0})$ & GnRH Agonist $(\boldsymbol{n}=\mathbf{9})$ & Bevacizumab $(\boldsymbol{n}=\mathbf{1 0})$ & $\boldsymbol{p}$ Value \\
\hline Bax expression & $1.0 \pm 0.0$ & $3.0 \pm 0.8$ & $3.1 \pm 0.8$ & $<0.05$ \\
\hline Cyt - expression & $1.0 \pm 0.0$ & $1.3 \pm 0.1$ & $1.3 \pm 0.1$ & $<0.05$ \\
\hline$B c l-2$ expression & $1.0 \pm 0.0$ & $0.4 \pm 0.2$ & $0.4 \pm 0.1$ & $<0.05$ \\
\hline$B c l-x l$ expression & $1.0 \pm 0.0$ & $0.8 \pm 0.2$ & $0.8 \pm 0.1$ & $<0.05$ \\
\hline
\end{tabular}

Values are mean \pm SEM.

Table 3. Ratios of mean values for Bcl-2, Bax and Cyt-c gene expressions.

\begin{tabular}{|l|c|c|}
\hline Group & Bcl-2:Bax & Bcl-2:Cyt-c \\
\hline Control $(n=10)$ & 1.00 & 1.00 \\
\hline GnRH Agonist $(n=9)$ & 0.14 & 0.32 \\
\hline Bevacizumab $(n=10)$ & 0.13 & 0.27 \\
\hline
\end{tabular}

with the control group $(p<0.001)$. Similarly, GnRH agonist statistically significantly increased expression of the Bax gene 3.0-fold ( $p<0.001), C y t-c$ gene 1.3fold $(p<0.001)$ and decreased expression of the $B c l-2$ gene 0.4 -fold $(p<0.001), B c l-x l$ gene 0.8 fold $(p=$ 0.002 ), compared with the control group. The level of change in anti-apoptotic and apoptotic gene expressions did not show statistically significant difference between bevacizumab and $\mathrm{GnRH}$ agonist group in endometrial explants $(p>0.05)$. In the bevacizumab and $\mathrm{GnRH}$ agonist groups, the ratios of $B c l-2: B a x$ (0.13 and 0.14 , respectively) and $B c l-2: C y t-c(0.27$ and 0.32 , respectively) were decreased compared with the control group (Table 3).

\section{DISCUSSION}

Treatment of endometriosis is based on surgical excision of endometriotic foci and medical suppression of ovarian steroid production. The choice of treatment modality depends on factors including the patient's age, severity of symptoms, location and size of the endometrial growth and fertility desire. Medical therapy includes oral contraceptives, progestins, and GnRH agonist, as well as androgen derivatives [15]. Because of high recurrence rates and adverse effect profiles, current treatment modalities are still not fully satisfactory [16-19]. Novel agents and treatment approaches are needed in order to improve our ability to treat endometriosis lesions.

In a normal mileu of humans, vasculature is maintained by the balanced presence of both pro angiogenic and anti-angiogenic factors. Endometriosis shifts the balance to favor angiogenic induction by increasing expression of angiogenic inducers, decreasing expression of angiogenic inhibitors, or a combination of both. Histopathological examinations reveal that angiogenesis is essential for survival and development of endometriotic lesions [20-22] and maturity of vessels in peritoneal lesion shows variations, depending on the stage of endometriosis. In early endometriotic lesions, high vascular density gives them a red-pink color. Black lesions are seen in late stages of disease and percentage of mature vessels is higher 
in those lesions $[23,24]$. This shows that maintenance and growth of early endometriotic lesions depend on newly formed blood vessels. Therefore, endometriosis and cancer growth have many similarities. These therapies cause a decrease in oxygen and nutrient supply to tumor cells by reducing tumor vascular density, perfusion and vascular permeability, which leads to apoptosis of tumor cells. Anti-angiogenetic drugs, which were used in many cancers, can be tried in endometriosis models. In animal models, the inhibition of endometriotic implant formation by blockage of angiogenesis yield encouraging results, but in some of them results were still unsatisfactory [25-30]. Vascular endothelial growth factor is an important vasoactive growth factor that plays a pivotal role in the regulation of physiological and pathological angiogenesis. It has been demonstrated that it is involved in pathophysiology of endometriosis. Therefore, inhibition of VEGF may be a potent therapeutic approach in treatment of endometriosis.

The aim of this study was to reveal the effect of bevacizumab, which is a VEGF antibody, on regression of endometriotic explants. For this purpose we have compared bevacizumab with GnRH agonist, which is a well known treatment modality for endometriosis. In this study, we observed that both GnRH agonist and bevacizumab decrease the endometriotic explants growth compared to the control group, but there were no significant difference between GnRH agonist and bevacizumab groups. Bevacizumab and GnRH agonist both cause an induction in apoptotic genes when compared with the control group, but no significant difference was shown between bevacizum$\mathrm{ab}$ and GnRH agonist groups. The effect of growth factor inhibition on endometriotic lesion regression was first studied by Laschke et al. [29]. They found that combined inhibition of VEGF, fibroblast growth factor and platelet-derived growth factor cause decrease in endometriotic lesion vascularization, but this effect was not seen with only VEGF antagonization [29].

Recently, the efficacy of bevacizumab on endometriotic lesion regression was studied by Ricci et al. [31] in endometriosis mice models. In that study, the induction of endometriosis was formed with three equal pieces of endometrial tissue instead of one piece and a control laparotomy (mice with surgically-induced endometriosis were treated with saline) for determination of explant viability was not performed. Although they failed to show a decrease in lesion numbers with bevacizumab, they demonstrated a decrease in total lesion volumes, cell proliferation, vascular density and an increase in apoptosis. However this therapeutic effect of bevacizumab was not compared with a known therapeutic modality [32]. At the present time GnRH agonist is one of the most widely used treatment modalities for endometriosis but can be used only for a limited time owing to unacceptable side effects such as climacteric symptoms and loss of bone density. As in many studies, our study confirmed that GnRH agonist caused an increase in apoptosis in endometrial cells besides hypoeustrogenic state formation [32-36]. Meresman et al. [33] also showed that GnRH agonist have a direct effect in endometrial cells cultures, by enhancing the percentage of apoptotic cells and decreasing the release of angiogenic factors such as VEGF and interleuking (IL)-1 $\beta$. Moreover, Bilotas et al. [33] exposed that the use of GnRH agonists enhance apoptosis in endometrial epithelial cell cultures by increasing $B a x$ and FasL expressions and decreasing $\mathrm{Bcl}-2$ expression.

Although the aim of our study was to evaluate the effectiveness of bevacizumab in treatment endometriosis, we found that bevacizumab caused significantly less adhesion formation compared to the control group, but we failed to demonstrate difference between bevacizumab and GnRH agonist. Moraloğlu et al. [37] studied the preventive effect of bevacizumab on adhesion formation. In that study, a rat uterine horn adhesion model was conducted and high and low doses of bevacizumab treatments were given. When compared with the control group, both low and high doses of bevacizumab reduced adhesion formation. Additionally, the high dose treatment did better than the low dose treatment in prevention of adhesion formation [37].

Bevacizumab was initially approved for the treatment of metastatic colon cancer and other solid tumors. It is important to note that treatment with bevacizumab may have potential adverse effects such as proteinuria, hypertension, thromboembolism and hemorrhages [38]. However, it should be kept in mind that these patients were mostly in terminal stage and were more prone to these adverse effects. In our study, we did not observe any adverse effect such as wound infection and weight loss after administration of the drugs.

In conclusion angiogenesis and salvage from apoptosis is required for development and maintenance of endometriotic lesions. Up to now, this has 
been the first study to compare bevacizumab with GnRH agonist. We observed that bevacizumab was effective as leuprolide acetate in regression of endometriotic lesions and caused less adhesion formation compared to the control group. Polymerase chain reaction studies revealed that a possible mechanism of action of bevacizumab could be induction of apoptosis. However, these observations are valid for rat endometriosis models and further studies are required in order to apply these observations to other species.

Declaration of Interest. This study was supported in part by Dokuz Eylül University Research Fund grant no. 2010.KB.SAG.042. The authors report no conflicts of interest. The authors alone are responsible for the content and writing of this article.

\section{REFERENCES}

1. Eskenazi B, Warner ML. Epidemiology of endometriosis. Obstet Gynecol Clin North Am. 1997; 24(2): 235-258.

2 D'Hooghe TM, Debrock S, Hill JA, Meuleman C. Endometriosis and subfertility: Is the relationship resolved? Semin Reprod Med 2003; 21(2): 243-254.

3. Vinatier D, Orazi G, Cosson M, Dufour P. Theories of endometriosis. Eur J Obstet Gynecol Reprod Biol. 2001; 96(1): 21-34.

4. McLaren J. Vascular endothelial growth factor and endometriotic angiogenesis. Hum Reprod Update. 2000; 6(1): 45-55.

5. Grothey A, Ellis LM. Targeting angiogenesis driven by vascular endothelial growth factors using antibody-based therapies. Cancer J. 2008; 14(3):170-177.

6. Selvakumaran M, Yao KS, Feldman MD, O'Dwyer PJ. Antitumor effect of the angiogenesis inhibitor bevacizumab is dependent on susceptibility of tumors to hypoxia-induced apoptosis. Biochem Pharmacol. 2008; 75(3): 627-638.

7. Carmeliet P, Dor Y, Herbert JM, Fukumura D, Brusselmans K, Dewerchin M, et al. Role of HIF$1 \alpha$ in hypoxia-mediated apoptosis, cell proliferation and tumour angiogenesis. Nature. 1998; 394(6692): 485-490.

8. Shaheen RM, Davis DW, Liu W, Zebrowski BK, Wilson MR, Bucana CD, et al. Antiangiogenic therapy targeting the tyrosine kinase receptor for vascular endothelial growth factor receptor inhibits the growth of colon cancer liver metastasis and induces tumor and endothelial cell apoptosis. Cancer Res. 1999; 59(21): 5412-5416.

9. Gebel HM, Braun DP, Tambur A, Frame D, Rana N, Dmowski WP. Spontaneous apoptosis of endometrial tissue is impaired in women with endometriosis. Fertil Steril. 1998; 69(6): 1042-1047.

10. Safaeian L, Abed A, Vaseghi G. The role of Bcl2 family proteins in pulmonary fibrosis. Eur $\mathrm{J}$ Pharmacol. 2014. pii: S0014-2999(14)00566-4. doi: 10.1016/j.ejphar. 2014.07.029.

11. Tesone M, Bilotas M, Barañao RI, Meresman G. The role of GnRH analogues in endometriosisassociated apoptosis and angiogenesis. Gynecol Obstet Invest. 2008; 66(Suppl 1): 10-18.

12. Vernon MW, Wilson EA. Studies on the surgical induction of endometriosis in the rat. Fertil Steril. 1985; 44(5): 684-694.

13. Linsky CB, Diamond MP, Cunningham T, Constantine B, De-Cherney AH, diZerega GS. Adhesion reduction in a rabbit uterine horn model using an absorbable barrier TC-7. J Reprod Med. 1987; 32(1): 17-20.

14. Keenan JA, Williams-Boyce PK, Massey PJ, Chen TT, Caudle MR, Bukovsky A. Regression of endometrial explants in a rat model of endometriosis treated with the immune modulators loxoribine and levamisole. Fertil Steril. 1999; 72(1): 135-141.

15. Crosignani $P$, Olive D, Bergqvist A, Luciano A. Advances in the management of endometriosis: An update for clinicians. Hum Reprod Update. 2006; 12(2): 179-189.

16. Matsuzaki S, Canis M, Murakami T, Dechelotte P, Bruhat MA, Okamura K. Immunohistochemical analysis of the role of angiogenic status in the vasculature of peritoneal endometriosis. Fertil Steril. 2001; 76(4): 712-716.

17. Mihalyi A, Simsa P, Mutinda KC, Meuleman C, Mwenda JM, D'Hooghe TM. Emerging drugs in endometriosis. Expert Opin Emerg Drugs. 2006; 11(3): 503-524.

18. Rice VM. Conventional medical therapies for endometriosis. Ann N Y Acad Sci. 2002; 955: 343-352. 
19. Child TJ, Tan SL. Endometriosis: Aetiology, pathogenesis and treatment. Drugs. 2001; 61(12): 1735-1750.

20. Groothuis PG, Nap AW, Winterhager E, Grümmer R. Vascular development in endometriosis. Angiogenesis. 2005; 8(2): 147-156.

21. Donnez J, Smoes P, Gillerot S, Casanas-Roux F, Nisolle M. Vascular endothelial growth factor (VEGF) in endometriosis. Hum Reprod. 1998; 13(6): 1686-1690.

22. Taylor RN, Lebovic DI, Mueller MD. Angiogenic factors in endometriosis. Ann N Y Acad Sci. 2002; 955: 89-100.

23. Nisolle M, Casanas-Roux F, Anaf V, Mine JM, Donnez J. Morphometric study of the stromal vascularization in peritoneal endometriosis. Fertil Steril. 1993; 59(3):681-684.

24. Matsuzaki S, Canis M, Murakami T, Dechelotte P, Bruhat MA, Okamura K. Immunohistochemical analysis of the role of angiogenic status in the vasculature of peritoneal endometriosis. Fertil Steril. 2001; 76(4):712-716.

25. Hull ML, Charnock-Jones DS, Chan CL, BrunerTran KL, Osteen KG, Tom BD, et al. Antiangiogenic agents are effective inhibitors of endometriosis. J Clin Endocrinol Metab. 2003; 88(6): 2889-2899.

26. Dabrosin C, Gyorffy S, Margetts P, Ross C, Gauldie J. Therapeutic effect of angiostatin gene transfer in a murine model of endometriosis. Am J Pathol. 2002; 161(3): 909-918.

27. Nap AW, Griffioen AW, Dunselman GA, BoumaTer Steege JC, Thijssen VL, Evers JL, et al. Antiangiogenesis therapy for endometriosis. J Clin Endocrinol Metab. 2004; 89(3): 1089-1095.

28. Becker CM, Sampson DA, Rupnick MA, Rohan RM, Efstathiou JA, Short SM, et al. Endostatin inhibits the growth of endometriotic lesions but does not affect fertility. Fertil Steril. 2005; 84(Supp1 2): 1144-1155.

29. Laschke MW, Elitzsch A, Vollmar B, Vajkoczy $\mathrm{P}$, Menger MD. Combined inhibition of vascular endothelial growth factor (VEGF), fibroblast growth factor and platelet-derived growth factor, but not inhibition of VEGF alone, effectively suppresses angiogenesis and vessel maturation in endometriotic lesions. Hum Reprod. 2006; 21(1): 262-268.
30. Novella-Maestre E, Carda C, Noguera I, RuizSaurí A, García-Velasco JA, Simón C, et al. Dopamine agonist administration causes a reduction in endometrial implants through modulation of angiogenesis in experimentally induced endometriosis. Hum Reprod. 2009; 24(5): 1025-1035.

31. Ricci AG, Olivares CN, Bilotas MA, Meresman GF, Barañao RI. Effect of vascular endothelial growth factor inhibition on endometrial implant development in a murine model of endometriosis. Reprod Sci. 2011; 18(7): 614-622.

32. Meresman GF, Bilotas MA, Lombardi E, Tesone M, Sueldo C, Baranao R. Effect of GnRH analogues on apoptosis and release of interleukin- $1 \beta$ and vascular endothelial growth factor in endometrial cell cultures from patients with endometriosis. Hum Reprod. 2003; 18(9): 1767-1771.

33. Bilotas M, Barañao RI, Buquet R, Sueldo C, Tesone M, Meresman GF. Effect of GnRH analogues on apoptosis and expression of Bcl-2, Bax, Fas and FasL proteins in endometrial epithelial cell cultures from patients with endometriosis and controls. Hum Reprod. 2007; 22(3): 644-653.

34. Meresman GF, Bilotas M, Buquet RA, Barañao RI, Sueldo C, Tesone M. Gonadotropin-releasing hormone agonist induces apoptosis and reduces cell proliferation in eutopic endometrial cultures from women with endometriosis. Fertil Steril. 2003; 80(2): 702-707.

35. Imai A, Takagi A, Tamaya T. Gonadotropin-releasing hormone analog repairs reduced endometrial cell apoptosis in endometriosis in vitro. Am J Obstet Gynecol. 2000; 182(5): 1142-1146.

36. Khan KN, Kitajima M, Hiraki K, Fujishita A, Sekine I, Ishimaru T, et al. Changes in tissue inflammation, angiogenesis and apoptosis in endometriosis, adenomyosis and uterine myoma after GnRH agonist therapy. Hum Reprod. 2010; 25(3): 642-653.

37. Moraloğlu O, Işik H, Kiliç S, Sahin U, Caydere M, Ustün $\mathrm{H}$, et al. Effect of bevacizumab on postoperative adhesion formation in a rat uterine horn adhesion model and the correlation with vascular endothelial growth factor and Ki-67 immunopositivity. Fertil Steril. 2011; 95(8): 2638-2641.

38. Shord SS, Bressler LR, Tierney LA, Cuellar S, George A. Understanding and managing the possible adverse effects associated with bevacizumab. Am J Health Syst Pharm. 2009; 66(11): 999-101. 